\title{
Erratum to: FAP-associated desmoid invasiveness correlates with in vitro resistance to doxorubicin
}

David E. Joyner $\cdot$ Sylvia H. Trang •

Albert J. Aboulafia • Timothy A. Damron •

R. L. Randall

Published online: 27 November 2009

(C) Springer Science+Business Media B.V. 2009

Erratum to: Familial Cancer (2009) 8:569-580 DOI 10.1007/s10689-009-9288-y

Unfortunately in Familial Cancer (2009) 8:569-580, one of the co-author's name had been misrepresented. The correct version is R. L. Randall and not R. Lor Randall as published.

The online version of the original article can be found under doi:10.1007/s10689-009-9288-y.

D. E. Joyner $(\bowtie) \cdot S$. H. Trang $\cdot$ R. L. Randall

SARC $^{\mathrm{TM}}$ Laboratory, Sarcoma Services,

Department of Orthopaedics and Huntsman Cancer Institute,

University of Utah, 2000 Circle of Hope,

Salt Lake City, UT 84112, USA

e-mail: david.joyner@hci.utah.edu

\section{A. J. Aboulafia}

Sinai Hospital Cancer Institute, Baltimore,

MD 21215-5271, USA

T. A. Damron

Department of Orthopaedics, SUNY Upstate Medical

University, Syracuse, NY 13202, USA 